\title{
POLÍTICAS PÚBLICAS DE EDUCAÇÃO AMBIENTAL: HISTÓRIA, FORMAÇÃO E DESAFIOS
}

\author{
Edson Grandisoli ${ }^{1}$ \\ Eliana Cordeiro Curvelo ${ }^{2}$ \\ Zysman Neiman ${ }^{3}$
}

Resumo: O presente artigo apresenta uma retrospectiva sobre os principais documentos internacionais e políticas públicas nacionais que tratam da Educação Ambiental (EA), além de analisar algumas visões sobre a sua prática. Em especial, são abordadas as possibilidades de atuação com a Educação Ambiental crítica e a aprendizagem baseada em investigação, projetos e/ou problemas, que possuem abordagens complementares e relacionadas ao uso do método científico na busca por caminhos que suportem transformações locais e globais por meio do debate cidadão, da participação e da colaboração. Por fim, os avanços e retrocessos referentes às diretrizes curriculares que norteiam a prática pedagógica no ensino formal são apresentados, e especialmente discutidos para o caso do currículo municipal de São Paulo, com foco nos desafios aos educadores em um cenário de constantes modificações das políticas públicas no ensino formal.

Palavras-Chave: Parâmetros Curriculares Nacionais; Base Nacional Comum Curricular; Educação Ambiental Crítica; Gestão Escolar; Cidadania Ambiental.

Abstract: This article presents a retrospective on the main international documents and national public policies that deal with Environmental Education (EE) in addition to analyzing some views about its practice. In particular, the possibilities of acting considering a Critical Environmental Education through an investigation, projects and/or problem-based learning are addressed, which encompasses complementary approaches related to the use of the scientific method in the search for support of local and global transformations through citizen debate, participation, and collaboration. Finally, the advances and setbacks regarding different curricular guidelines related to pedagogical practices in formal education are presented, with a special focus on the case of the São Paulo municipal curriculum, including the challenges to educators in a scenario of constant changes in public policies on the formal education scenario.

Keywords: National Curriculum Parameters; Common National Curriculum Base; Critical Environmental Education; School Management; Environmental Citizenship.

\footnotetext{
1 Instituto de Energia e Ambiente da USP, Grupo de Acompanhamento e Estudos em Governança Ambiental (GovAmb). E-mail: edsongrandisoli@gmail.com. Link para o Lattes: http://lattes.cnpq.br/6140708266941356

2 Instituto Federal do Paraná. E-mail: curvelo.eliana@gmail.com.

Link para o Lattes: http://lattes.cnpq.br/2989553954221707

3 Universidade Federal de São Paulo. E-mail: zneiman@gmal.com.

Link para o Lattes: http://lattes.cnpq.br/6435341856481082
} 


\section{Introdução}

Estudos e pesquisas acerca das políticas públicas em educação, da gestão educacional, formação continuada de professores entre outros temas são amplas. Esses estudos demonstram a diversidade das perspectivas, concepções e cenários da educação existentes em nosso país. São muitas as vozes que podemos ouvir, advindas das inúmeras pesquisas e estudos que, para muitos, acabam se tornando ruídos e, ao invés de mobilizar, imobilizam os partícipes que estão envolvidos diretamente no processo educacional bem como indiretamente aos indivíduos que passam a ter suas opiniões e percepções sobre o que acontece dentro do espaço escolar.

Esse arcabouço conceitual pode ser ilustrado metaforicamente pela instalação Babel (2001), do artista Cildo Meireles (Figura 1). A instalação é feita com rádios e são ligados todos ao mesmo tempo, emitindo sons - notas e ruídos; em níveis de altura - agudos e graves; de intensidades - fortes e fracos; de timbres - as diferentes fontes sonoras, estilos, programas entre outras emissões de intensidades, altura om, nos revela um edifício feito de rádios. Quando olhamos a base de Babel podemos observar que os rádios da base são antigos e conforme vão se utilizando de outros rádios como tijolos, os rádios vão se modernizando.

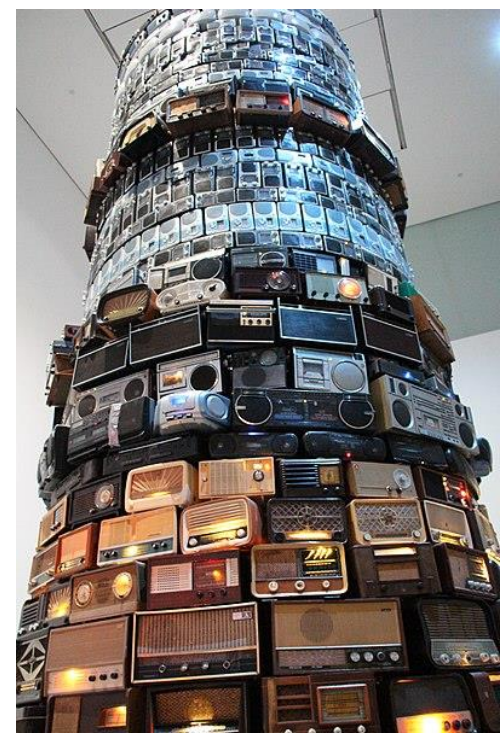

Figura 1: 'Babel', Cildo Meireles (2001)

Fonte: Imagem licenciada por Creative Commons Attribution 2.0 Generic license. (https://commons.wikimedia.org/wiki/File:London - Tate Modern (14).jpg)

O escritor Walter Benjamin fez uma leitura da obra "Angelus Novus", 1920, de Paul Klee (Figura 2), e nela descreve a imobilidade do anjo frente aos desafios do início do séc. XX. Em pleno século XXI, esta mesma obra é revisitada por Zygmunth Bauman, escritor conhecido pelo conjunto de sua obra a respeito da modernidade líquida e, em sua obra póstuma, nos deixou o conceito de retrotopia. Para o autor, a retrotopia é a utopia do passado e uma busca de elementos que nos deem conforto, mesmo que ilusórios. Com sua 
habilidade, Bauman nos situa e nos apresenta um mundo povoado por ideias e práticas glorificadas num passado que não nos ajuda a realizar o futuro.

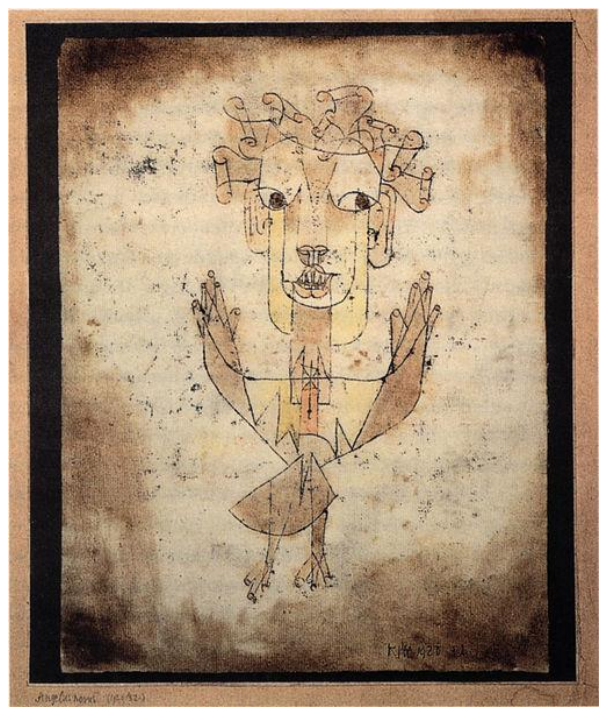

Figura 2: Angelus Novus - Paul Klee (1920).

Fonte: Wikimedia Commons, acervo de conteúdo livre da Wikimedia Foundation (https://commons.wikimedia.org/wiki/File:Paul Klee Angelus Novus 1920.jpg)

Os profissionais da educação pública, seja como gestores públicos, servidores públicos ou agentes públicos, vêm se imiscuindo de diversas formas, por meio de discursos apreendidos na pluralidade e complexidade dos conhecimentos produzidos e propostos pelos decisores políticos. Para Barroso (2009, p.991), este excesso de instâncias decisórias se apresenta "como uma espécie de placebo junto à opinião pública para sustentar a convicção de que as medidas tomadas constituem as 'terapêuticas' mais ajustadas aos problemas" que necessitam de resolução no tecido educacional. Uma série de metas, estratégias e determinações - dinâmicas de forma exponencial, abrindo tergiversações para que o setor privado 'norteie' o conhecimento e a aplicação adequada destas diretrizes educacionais, sem perceber as orientações neoliberais que subjazem às dinâmicas de aplicação.

Sendo muito penoso compreender as dinâmicas que deverão estar nos espaços educacionais, os atores da educação fragmentam suas percepções devido à imobilidade (Angelus Novus) de tantos conhecimentos e informações que impedem sua reflexão e ação pedagógica, visto que

quando quantidades crescentes de informação são distribuídas a uma velocidade cada vez maior, torna-se progressivamente mais difícil criar narrativas, ordens ou sequências de desenvolvimento. Os fragmentos ameaçam se tornar hegemônicos. Isso tem consequências para as maneiras como nos relacionamos com o conhecimento, o trabalho e o estilo de vida num sentido amplo (BAUMAN, 2010, p.35). 
Fragmentos que podem ser interpretados como a "diversidade de fontes, formas e conteúdo de conhecimento, a escolha da informação, dos dados, dos estudos, das conclusões ou recomendações a utilizar permanece eminentemente política, pouco racional e fortemente condicionada por interesses e lógicas de poder" (BARROSO, 2009, p. 989), influenciando diretamente aos atores/sujeitos adquirirem comportamentos associados à resistência, sendo considerados mais como servidores do que agentes públicos no reconhecimento das novas configurações na área educacional dos últimos anos em nosso país.

Entendemos aqui o comportamento de resistência, devido ao incessante número de reformas, adequações, propostas e iniciativas para mudanças das práticas pedagógicas, currículos, avaliações e afins, que "as proposições políticas de ações e de regulação do Estado Brasileiro estão, aparentemente, sem eficácia em seu propósito de atendimento às demandas da sociedade atual no Brasil' (LEMES, 2016, p.1618).

Apesar disto, ainda, é preciso acreditar em possibilidades. Segundo Barroso (2005, p.727), as propostas ao papel regulador do Estado servem para

Demarcar as propostas de "modernização" da administração pública das práticas tradicionais de controlo burocrático pelas normas e regulamentos que foram (e, são ainda) apanágio da intervenção estatal. Neste sentido, a "regulação" (mais flexível na definição dos processos e rígida na avaliação da eficiência e eficácia dos resultados) seria o oposto da "regulamentação" (centrada na definição e controlo a priori dos procedimentos e relativamente indiferente às questões de qualidade e eficácia dos resultados).

Como o próprio autor expõe essa sutil diferença entre os dois termos não são rigorosas na linguagem científica, portanto também no senso comum podem existir imbricações no seu uso e em suas diversas interfaces na área educacional. Coloca-se assim a importância da regulação do Estado e de seus órgãos executores; entretanto, é preciso distinguir se serão usadas as regulações conservadoras ou as regulações transformadoras. Independentemente do tipo, o que averiguamos é que nos últimos anos foram 'identificadas perturbações' no espaço escolar no que se refere à garantia de educação aos cidadãos brasileiros.

Neste cenário, avaliações internas e externas estão sendo realizadas. Sabe-se que são de suma importância para definir estratégias e dinâmicas no espaço escolar pelos atores/sujeitos poderem garantir o ensino e a aprendizagem. Mas os envolvidos vêm perdendo o sentido e significado devido ao ambiente no qual se insere o principal ator, que deveria ser o protagonista. $O$ excesso de trabalho assumido pelos professores e as informações sem as devidas interpretações tornam a melhoria das práticas pedagógicas ineficazes para os profissionais da educação. 
Atualmente, percebe-se que há uma confusão de informações decorrente das diversas interpretações a que se tem dado às novas orientações. O respeito à hierarquia pode parecer que melhora a coordenação, mas existem disfunções como se vê a seguir:

cada nível da hierarquia produz um potencial bloqueio de comunicação, porque os subordinados relutam em comunicar qualquer coisa que possa ser vista com maus olhos pelos superiores; na verdade, provavelmente há a tendência de se comunicar só aquilo que os fazem parecer bem ou aquilo que acham que seus superiores, desejam ouvir (BLAU; SCOTT, 2003; apud HOY, 2015, p.88).

Segundo Hoy e Miskel (2015), as estruturas escolares apresentam muitas maneiras de desenvolver e aplicar o trabalho, sendo dividido por regras e tarefas. Esses devem ser coordenados, porém as regras reforçam e preservam a apatia por explicitarem o nível mínimo aceitável. Alguns funcionários permanecem apáticos, pois sabem o quão suas funções são inseguras. Quando a apatia se conjuga com a hostilidade, o cenário está pronto para a "sabotagem organizacional", surgindo regulamentos que podem ser percebidos por um legalismo extremo em que "cria um clima insalubre nas escolas" (p.90).

Neste contexto, os padrões burocráticos se multiplicam e não respondem adequadamente a tantas mudanças que estão sendo realizadas. $\mathrm{O}$ conceito de eficiência e eficácia se concentra nos papéis e funções das estruturas rígidas. Preparar os atores/sujeitos do cenário educacional para que desenvolvam um padrão profissional de suas atividades se torna essencial, independentemente se as novas orientações devam ser assimiladas. Esta necessidade é importante, inclusive, para se ter a criticidade sobre essas orientações dentro das realidades e cotidianos que encontramos dentro das escolas. Isso não é diferente para a Educação Ambiental nesses espaços, que acaba sendo "enquadrada" de muitas formas, deixando de cumprir seu papel emancipatório e de "esperançar" as presentes e futuras gerações. Esses e outros aspectos, dentro de uma proposta de revisão histórica crítica, serão mais explorados a seguir.

\section{A Educação Ambiental e sua trajetória histórica}

Desde a Conferência Mundial sobre o Meio Ambiente Humano (Conferência de Estocolmo), em 1972, as Nações Unidas já definiram algumas diretrizes que embasariam a criação do Programa Internacional de Educação Ambiental (PIEA) pela UNESCO, em 1975, na cidade de Belgrado. Na Conferência iniciou-se a discussão sobre Educação Ambiental de forma sutil, porque os países em desenvolvimento ainda não tinham a pauta do meio ambiente entre suas prioridades, uma vez que estavam focados nos avanços 
econômicos como estratégia para combater miséria e em continuar a se desenvolver (ABREU et al., 2010).

A Conferência de Estocolmo trouxe sete pontos de extrema importância e vinte e seis princípios, como uma forma de aproximar o meio ambiente dos direitos humanos. Foi um evento histórico, fazendo com que discussões sobre meio ambiente estivessem presentes em agendas políticas de diversos países do mundo (GURSKI et al., 2012). Já a carta de Belgrado ficou conhecida como um marco na questão ambiental no mundo. Nela constam necessidades e os desejos que a população almeja: temas importantes como a erradicação da pobreza, do analfabetismo, da poluição, entre outros que os cidadãos desejam ver solucionados.

Após Estocolmo (1972) e Belgrado (1975) pode-se citar, como as principais reuniões que ocorreram no mundo, a de Tbilisi em 1977, a de Moscou em 1987, a do Rio de Janeiro em 1992 e a RIO + 20 em 2012.

A Conferência Intergovernamental de Educação Ambiental ocorreu em Tbilisi, Geórgia (URSS) sendo organizada pela UNESCO em 1977. Foi considerado um grande marco para Educação Ambiental (EA), pois nela foram debatidos e aprovados princípios para este campo no ensino formal e não formal (SILVA et al., 2006), que compõe a "Declaração de Tbilisi", com mais de 40 recomendações. Elaborado pelo Programa de Meio Ambiente da ONU em parceria entre a UNESCO e com a colaboração de especialistas foram definidas as finalidades da Educação Ambiental que passaram a ter, para além da dimensão de conservacionismo prevalecente até então, uma abordagem mais integradora, crítica e inter-relacionada das questões humanas e ambientais, incorporando suas dimensões econômica, política, social, cultural, ética, ideológica. Segundo Gadotti (2009), teve como escopo

promover a compreensão da existência e da importância da interdependência econômica, social, política e ecológica; proporcionar a todas as pessoas a possibilidade de adquirir os conhecimentos, o sentido dos valores, o interesse ativo e as atitudes necessárias para protegerem e melhorarem o meio ambiente e induzir novas formas de conduta, nos indivíduos e na sociedade, a respeito do meio ambiente.

No ano de 1987, em Moscou (Rússia), foi realizado um Congresso Internacional sobre a Educação e Formação Relativas ao Meio Ambiente. Nele, os princípios da Conferência de Tbilisi foram reafirmados e os avanços que ocorreram na década (1977-1987) foram avaliados. Um dos objetivos do congresso, segundo Ramos (1996), foi o de inserir a Educação Ambiental em todos os níveis de ensino, algo que já havia sido discutido em Belgrado e Tbilisi, mas que ainda não havia sido colocado efetivamente em prática.

No Brasil, especificamente no Rio de Janeiro, entre 3 e 14 de junho de 
Desenvolvimento, que ficou conhecida como Rio 92 e/ou Eco-92. Essa conferência ficou marcada por diferenças entre os países desenvolvidos e subdesenvolvidos, com estratégias diferentes, já que os países mais ricos não assumiram suas responsabilidades para que fosse viabilizado 0 desenvolvimento sustentável (OLIVEIRA, 2017). O chamado "Desenvolvimento Sustentável" foi construído por meio de um acordo político, juntamente com a sociedade civil, algumas ONGs e movimentos sociais no Fórum Global. Segundo Oliveira (2011a e 2011b), era preciso "pensar globalmente, agir localmente".

"A Carta da Terra" foi um documento de grande importância, tendo evoluído de um modelo (esboço) elaborado em 1987, mas que foi aprofundado, ainda preliminarmente, na Rio-92. Foi discutida por mais 8 anos pela "Comissão da Carta da Terra", criada em 1997, com o intuito de conduzir a redação até a sua finalização e aprovação em 2000. Esse processo teve a participação de organizações não governamentais e representantes da sociedade civil, sendo o documento ratificado pela UNESCO e definitivamente aprovado pela ONU em 2002. Também no âmbito da Rio-92 foi aprovada a Agenda 21, "um instrumento de planejamento para a construção de sociedades sustentáveis, em diferentes bases geográficas, que concilia métodos de proteção ambiental, justiça social e eficiência econômica" (BRASIL, s.d).

Em 2012, novamente na cidade do Rio de Janeiro, aconteceu outra Conferência das Nações Unidas, que ficou conhecida como "Rio+20". Essa Conferência reuniu 193 delegações diplomáticas e reforçar o compromisso dos Estados com o desenvolvimento sustentável. Seu objetivo foi o de assegurar o compromisso político com o desenvolvimento sustentável, avaliando o progresso que tinha acontecido até então, corrigir as lacunas que ainda existiam e colocar em prática alguns desafios que surgissem. O foco principal foi a economia verde no contexto do desenvolvimento sustentável e na erradicação da pobreza e no quadro institucional para que esse desenvolvimento possa acontecer (TÁVORA, 2012).

As Conferências das Nações Unidas e os seus documentos finais respectivos sempre refletem o equilíbrio de forças internacionais quando foram realizadas (OLIVEIRA, 2012).

Com resultado de todos esses debates, a Educação Ambiental assistiu, ao longo do final do século $X X$ e início do século $X X I$, uma contínua e crescente evolução de conceitos e práticas, que ampliaram seu escopo de influência na formação de uma nova ética e atitudes em relação ao meio ambiente. A seguir, apresenta-se uma síntese das principais tendências da Educação Ambiental na atualidade, principalmente no que concerne aos desafios dos educadores no ensino formal de inserirem essa temática ante as reformas curriculares recentemente implementadas no Brasil. 


\section{Algumas visões de Educação Ambiental}

A Educação Ambiental é o nome que historicamente se convencionou dar às práticas educativas relacionadas ao debate das questões ambientais, cuja prática possibilita às pessoas apreender novos valores, com vistas às transformações nas atitudes individuais e coletivas em busca de uma melhor qualidade de vida, para todos.

Esse campo tem abarcado uma grande variedade de olhares e práticas. Isso se relaciona, entre outros motivos, à grande diversidade de contextos associados aos diferentes desafios socioambientais, os quais demandam soluções que vão muito além de uma visão simplificada de preservação, uma vez que envolvem múltiplas dimensões éticas, estéticas, morais e culturais, econômicas etc.

Kopnina (2020) traça um paralelo elegante entre alguns documentos oficiais internacionais e a evolução dos processos em Educação Ambiental, considerando desde a publicação do Limites do Crescimento (1972) até a instituição dos Objetivos de Desenvolvimento Sustentável pela UNESCO (2015). Nesse intervalo de 48 anos, entre os quais ocorreram os Congressos supracitados, o olhar se transportou da preocupação com o crescimento populacional, passando por uma abordagem educacional mais preservacionista ligada à Ecologia e aumento da consciência sobre o mundo natural e caminhos de enfrentamento da crise civilizatória, até o advento da Década da Educação para o Desenvolvimento Sustentável e dos ODS, momentos diretamente oriundos do Relatório Brundtland (1987) e da Rio 92 (1992).

Todos esses documentos e seus respectivos momentos históricos influenciaram diretamente no como pensamos e fazemos Educação Ambiental e, apesar dessa trajetória histórica, essas múltiplas abordagens ainda coexistem.

Segundo Sorrentino et al. (2005), a Educação Ambiental objetiva educar os cidadãos para exercer a cidadania, construindo possibilidades e responsabilidades pelo mundo que almeja habitar.

Otero e Neiman (2015, p.21) afirmam que a Educação Ambiental tem um importante papel na contribuição para a melhoria das condições de vida das comunidades humanas, atuando "na formação de políticas ambientais, fomentando os debates, e contribuindo para um diálogo permanente na tentativa de tornar os cidadãos agentes transformadores da sociedade".

Atualmente há uma diversidade de nomenclaturas complementares à Educação Ambiental e algumas correntes sobre a concepção e a intenção de EA. Philippi Junior et al. (2000) apontam reflexões sobre esse modo de ensinoaprendizagem, a interdisciplinaridade, e a indicam como um caminho para se entender e trabalhar a complexidade nas questões ambientais. Silva Thiesen (2008) defende que para se entender melhor a relação entre seu todo e as partes, é fundamental a constituição de um olhar interdisciplinar sobre a realidade. 
Para Layrargues e Lima (2014), existem três macrotendências políticopedagógicas disputando o campo da Educação Ambiental no Brasil. São elas: as conservacionistas, a pragmática e a crítica. A "Educação Ambiental crítica, transformadora e emancipatória emerge da pedagogia crítica, que tem seu ponto de partida na teoria crítica de interpretação da realidade social" (LOUREIRO et al., 2009, pp. 85-6).

$\mathrm{Na}$ escola, por meio da relação entre docentes e discentes, é possível construir uma visão crítica, desde que ela esteja integrada com a realidade vivenciada por seus alunos. Para Freire (1996), se não for assim a escola se torna mera reprodutora de conceitos abstratos e rígidos, vazia, e sem sentido, não oferecendo significados que possam transformar a visão de mundo.

A Educação Ambiental, para Guimarães (2004), deve promover ambientes educativos com intervenção sobre a realidade e seus problemas, abrindo novas possibilidades de compreensão sobre os complexos problemas socioambientais. No entanto, o autor concorda que apresentar soluções não é uma tarefa simples, pois elas necessitam de pensamento igualmente complexo e de ações interdisciplinares. É preciso promover um debate que aproxime indivíduo e sociedade, sujeito e objeto, de modo a ofertar aos alunos uma visão do todo, em um movimento dialógico (FREIRE, 1998; LEFF, 2000; LAYRARGUES, 2006).

Apesar da variedade e das mudanças teórico-prática-metodológicas ao longo da história, é ainda hoje possível identificar-se, pelo menos, três linhas gerais de atuação em Educação Ambiental, as quais já haviam sido sugeridas e descritas na forma de uma breve tipologia por Lucas (1980). Segundo o autor, as três linhas de atuação em Educação Ambiental são: a Educação Ambiental sobre o ambiente (about the environment), no ambiente (in the environment) e para o ambiente (for the environment). Apesar dessa tipologia ter sido proposta há exatos 40 anos, ela ainda é extremamente atual ao se analisar a evolução das práticas educacionais e suas possíveis combinações.

A Educação Ambiental sobre o ambiente, valoriza aspectos cognitivos e foca na transmissão de informação sobre diferentes desafios socioambientais, incluindo suas causas, principais atores responsáveis e alguns caminhos para sua resolução. Essa linha de atuação se relaciona diretamente com o ensino de Ciências e Ecologia, buscando melhorar nossa relação com o ambiente por meio de dados, informações e conceitos. Apesar de ainda estar presente em muitos momentos nos diferentes ciclos educativos (em especial na educação formal), a Educação Ambiental sobre o ambiente, pautada por uma aprendizagem passiva, notadamente mobiliza de forma insuficiente habilidades voltadas para uma efetiva compreensão e busca por resoluções de diferentes desafios.

A Educação Ambiental no ambiente está relacionada à fundamental necessidade de contato com a natureza em ambientes mais preservados, na busca por uma compreensão maior sobre sua importância para nossas vidas e as de outras espécies. Estudos do meio, visitas guiadas, atividades de campo

revista brasileira educação ambiental 
investigativas, trilhas interpretativas, entre outras estratégias, são capazes de trabalhar de forma combinada tanto o componente cognitivo quanto o afetivo, sendo esse último considerado fundamental para mudanças de atitudes e comportamentos pessoais e coletivos. Em uma pesquisa realizada por Kellert (2002. P.120), ele afirma que

[...] as experiências (na natureza) aumentaram significativamente suas capacidades de lidar com os desafios e adversidades. Dois-terços a três-quartos relataram melhora na autoestima, independência, autonomia, iniciativa, tomada de decisão e habilidades relativas à resolução de problemas.

Por fim, a Educação Ambiental para o ambiente possui propósitos de conservação do que já existe e, além disso, da recuperação de espaços degradados. Ou seja, para além da busca de um melhor relacionamento com a natureza e de soluções baseadas em adaptação e mitigação, a educação para o ambiente tem uma finalidade regenerativa, restaurativa, na direção da recomposição dos ambientes e suas relações, pontos já presentes na Carta de Belgrado de 1975 e que dialogam recentemente com a Década da ONU da Restauração de Ecossistemas (2021 a 2030).

Pode-se afirmar que esse desafio, tanto técnico quanto educacional, vai ao encontro de tendências mais recentes ligadas à adoção de metodologias ativas de aprendizagem (MORAN, 2015; BACICH; MORAN, 2018). A aprendizagem baseada em investigação, projetos e/ou problemas possui abordagens complementares e relacionadas ao uso do método científico na busca por caminhos que suportem transformações locais e globais por meio da participação e da colaboração. Ou seja, educar para o ambiente significa assumir uma postura mais protagonista e cidadã, garantindo o envolvimento de diferentes atores e conduzindo a um processo legítimo de aprendizagem social (JACOBI; TOLEDO; GRANDISOLI, 2016; GRANDISOLI, 2018; 2019).

Para que a Educação Ambiental para o ambiente possa ocorrer de forma efetiva, é importante lançar mão de novas abordagens educacionais mais ativas e que resignificam os processos de ensino e de aprendizagem.

Ensinar e aprender por investigação, projetos e/ou problemas, por exemplo, depende de uma compreensão aprofundada de sua própria realidade socioambiental. Bons diagnósticos possuem base participativa e colaboram diretamente para determinação de objetivos claros e assertivos, os quais, por sua vez, devem dialogar com as intervenções e múltiplas formas de avaliação (quanti e/ou qualitativas).

Apesar de parecer um processo simples, exige muito cuidado, planejamento, prática e experiência. Com frequência, os desafios socioambientais a serem trabalhados são definidos pelos educadores ou outros representantes, sem conhecer sua relevância e representatividade junto à comunidade. Partindo desse ponto, existe a tendência em determinar-se inúmeros objetivos, o que dificulta a criação de estratégias de intervenção 
eficientes e, consequentemente, impede uma avaliação competente dos resultados alcançados.

É muito provável que essas limitações metodológicas estejam na base dos problemas relacionados à permanência e continuidade de projetos e programas de Educação Ambiental nos ensinos formal, não-formal e informal. A questão é: como esperamos engajar e co-responsabilizar os educandos se os objetivos não são claros e coletivos, as intervenções não são assertivas e os resultados não são devidamente aferidos? Parte fundamental dessa problemática reside na ainda deficiente qualificação de educadores, agentes ambientais, gestores e todos os que se ocupam das questões socioambientais, apesar da significativa trajetória da Educação Ambiental na legislação e políticas públicas implementadas e em vigor no Brasil.

\section{A inserção da Educação Ambiental no ensino formal do Brasil}

Foi nas décadas de 1980 e 1990 que o Brasil conseguiu organizar as Bases Legais para uma relação entre a educação e meio ambiente, com a aprovação de diversas leis e políticas públicas ambientais (CZAPSKI, 1998). Desde 1988, a Constituição Federal Brasileira, em seu capítulo VI dedicado ao meio ambiente, no artigo 225, afirma que "todos têm direito ao meio ambiente ecologicamente equilibrado". O inciso VI deixa bem claro que compete ao Poder Público "promover a Educação Ambiental em todos os níveis de ensino e a conscientização pública para a preservação do meio ambiente".

Em 1999 é aprovada a Política Nacional de Educação Ambiental PNEA (Lei 9795/99), regulamentada em 2002, e que determina a inclusão da Educação Ambiental em todos os níveis de ensino (BARBOSA, 2008), devendo estar presente nas atividades escolares, por se constituir em um exercício para a cidadania. A PNEA define que a Educação Ambiental

compreende processos por meio dos quais o indivíduo e a coletividade constroem valores sociais, conhecimentos e habilidades, atitudes e competências voltadas para conservação do meio ambiente, bem de uso comum do povo, essencial à sadia qualidade de vida e sua sustentabilidade.

A PNEA prevê a garantia do direito à Educação Ambiental a todos os brasileiros, e tem como princípio básico uma abordagem democrática, humanística e, principalmente, holística, constituindo-se em parte essencial e permanente da educação nacional. Proporciona uma compreensão abrangente do meio ambiente nos seus diversos e e complexos contextos com a garantia da democratização da informação ambiental e o estímulo à criação de uma consciência crítica sobre as dimensões ambientais e sociais, fazendo um chamamento a todos para a construção coletiva de uma cidadania preocupada com o futuro da Humanidade (BRASIL, 1999). 
O Órgão Gestor (OG) da PNEA, composto pelos Ministérios do Meio Ambiente (MMA) e da Educação (MEC), só foi instituído em junho de 2003, juntamente com seu Conselho Assessor - instância de controle social dessa política pública, cuja composição compreende a representação de treze setores da sociedade. Em abril de 2004, representantes da Educação Ambiental se reuniram em Goiânia e reafirmaram uma gestão democrática e compartilhada para que a participação e o exercício do controle social fossem estimulados. A parceria dos representantes estaduais e municipais com o OG iniciou o processo de consolidação da Educação Ambiental em todo o território nacional.

O OG, juntamente com o Programa Municípios Educadores Sustentáveis (MES), promoveram ações integradas potencializando a Educação Ambiental, além de divulgar informações importantes para a questão ambiental, sempre com o objetivo de "fixar" a potencialização da Educação Ambiental em todo o país (BARBOSA, 2008).

A valorização do diálogo das políticas públicas juntamente com $O G$ e outros colaboradores, permitiram que existissem várias ações de Educação Ambiental, realizadas em âmbito federal, estadual e municipal. Desta forma, houve uma tentativa de descentralização da responsabilidade de estimular a educação para a sustentabilidade, ação que, teoricamente, permitiu maior participação na direção de uma Educação Ambiental popular, aprovado pelo Fórum Global das Organizações não Governamentais, paralelo à Rio-92 (JACOBI et. al, 2011).

Segundo Novicki e Souza (2010), no Brasil, a temática ambiental vem sendo inserida gradualmente nos espaços formal e não formal de ensino. Estritamente ao ensino formal, existem hoje no Brasil dois documentos norteadores que abordam a questão ambiental no currículo escolar: as Diretrizes Curriculares Nacionais para a Educação Ambiental (DCNEA), e os Parâmetros Curriculares Nacionais (PCN). A Base Nacional Comum Curricular (BNCC), mais recente, como veremos não abordar o tema.

Antes mesmo da aprovação da PNEA e para atender ao disposto no Artigo 225 da Constituição Brasileira, a abordagem da Educação Ambiental foi inserida no ensino básico a partir da aprovação dos Parâmetros Curriculares Nacionais (PCN), em 1998. O "Tema Transversal Meio Ambiente", sugerido pelos PCN garantia uma abordagem interdisciplinar no âmbito escolar que cumpria a necessidade do debate extremamente importante para os tempos atuais, tendo a sustentabilidade como princípio fundamental. A principal função do trabalho com o esse tema transversal, segundo os PCN, é

contribuir para a formação de cidadãos conscientes, aptos a decidir e a atuar na realidade socioambiental de modo comprometido com a vida, com o bem-estar de cada um e da sociedade, local e global. Para isso, é necessário que, mais do que informações e conceitos, a escola se proponha a trabalhar com atitudes, com formação de valores, com o ensino e a aprendizagem de habilidades e procedimentos. 
Apesar de vigorar por duas décadas, os PCN encontram grande dificuldade de se consolidar de fato nos currículos escolares, principalmente pela descontinuidade de incentivos dos órgãos federais de definição de políticas públicas, ao longo do início dos anos 2000, sendo, por fim, substituídos pela Base Nacional Comum Curricular (BNCC) para o ensino fundamental, homologada em dezembro de 2017 e na qual os temas transversais (a Educação Ambiental, inclusive) deixam de estar contemplados de maneira explícita.

A BNCC, que teve 3 versões preliminares divulgadas para consulta pública, antes da homologação da versão final, deverá nortear os currículos das escolas de todo o Brasil, desde as da rede pública de ensino até as da rede particular, contendo os conhecimentos essenciais, as competências e as aprendizagens pretendidas para todos os alunos da Educação Básica do Brasil, desde a educação infantil até o ensino médio. Constitui-se em um documento normativo que contém um conjunto de elementos essenciais de aprendizagem a que todos os alunos do ensino básico têm direito. Seu objetivo é orientar a elaboração dos planos de estudos e currículos das escolas públicas e privadas; especificar uma política para a formação de professores; a produção de materiais didáticos e avaliações com o objetivo de elevar a qualidade da educação em todo o Brasil, promovendo a equidade nos sistemas educacionais, em busca de uma sociedade democrática, justa e inclusiva (BRASIL, 2017).

Vale destacar que análises feitas por Andrade e Piccinini (2017) apontam que a segunda versão apresentava alguns pontos que deveriam ser melhor abordados frente à questão ambiental, e que mais avanços seriam necessários, já que ainda existem disciplinas que não abordam essa temática. $\mathrm{Na}$ terceira versão, apresentada, em 6 de abril de 2017, pode-se verificar que não havia mais menções sobre Educação Ambiental, algo que estava previsto em algumas competências nas duas primeiras versões que foram produzidas $e$ disponibilizadas. A versão final, referente ao ensino fundamental, aprovada em 15 de dezembro de 2017, consolidou a ausência do campo. O mesmo ocorre na versão referente ao Ensino Médio aprovada em 14 de dezembro de 2018.

A despeito de tudo que prevê a legislação em vigor, vale a pena registrar, de uma forma bem enfática, que a BNCC se furtou a abordar alguns temas transversais de ensino da forma que deveria, em especial não dando a devida relevância à Educação Ambiental que é citada apenas uma única vez em todo o documento. Isso acaba colocando a responsabilidade de inserir e abordar esta temática de forma contextualizada, aos sistemas de ensino municipais e estaduais e às próprias escolas (OLIVEIRA; NEIMAN, 2020).

$O$ desafio que se instalou, segundo Bardon et al. (2017), envolve oito pontos importantes: formação continuada de professores; formação inicial de professores; avaliação; livros didáticos; currículos; Base do ensino médio; gênero e sexualidade; revisão da Base. Vale mencionar que a revisão da BNCC ocorrerá após cinco anos de sua implementação, sendo prevista assim

revista brasileira educação ambiental 
apenas para 2025, pois estimava-se que os Estados e municípios conseguiriam implementá-la plenamente até 2020.

Também aprovada em 2017, a reforma do ensino médio prevê que as escolas passem a oferecer diversos percursos formativos, para os alunos possam optar por uma formação com foco em línguas, matemática, ciências naturais, humanidades ou formação técnica. Supostamente, na BNCC referente à essa fase do ensino, haveria a possibilidade de inserir a Educação Ambiental em todos esses itinerários formativos, colocando-a de uma forma interdisciplinar, ou seja, dentro de atividades propostas em cada disciplina, uma vez que parte da formação (40\%) será voltada para a ênfase escolhida e o restante do tempo, para a formação comum. No entanto, sem estar explícita essa orientação na BNCC, isso poderá ocorrer aquém do desejado e necessário frente à multiplicidade das crises socioambientais contemporâneas.

As Diretrizes Curriculares Nacionais (2012) é um documento de mais de 500 páginas como uma exigência constitucional, como é observado nos artigos 22 e 210 da Constituição Federal de 1988, com orientações para os sistemas de ensino, sua organização, articulação e desenvolvimento. Este documento traz diversos pareceres e resoluções dos mais variados assuntos dentro da educação, dentre eles as Diretrizes Curriculares Nacionais para a Educação Ambiental (DCNEA). Para a fundamentação e finalização das DCNEA, foi necessária a participação dos sistemas de ensino, sociedades, eventos que discutiram a Educação Ambiental, como, por exemplo, o VII Fórum Brasileiro de Educação Ambiental realizado na Bahia. Elas deveriam ser observadas por todos os estabelecimentos de ensino do país, para que neles ocorresse a implementação da Educação Ambiental nos diversos níveis educacionais.

No documento, dentro de todos os itens é citado que a Educação Ambiental é independente, devendo ser considerada por políticas públicas obrigatoriamente presentes em todos os níveis educacionais. Dentro dessas políticas públicas são abordadas as iniciativas do Ministério da Educação, dentre elas a elaboração de parâmetros em Ação-meio ambiente nas escolas, realização de cursos de Formação continuada de professores em Educação Ambiental, sendo presencial desde 2004 e a distância a partir de 2008, entre outras iniciativas. No entanto, a aprovação na BNCC tornou inócuas essas recomendações dos DCNEA, uma vez que todos os seus pressupostos também foram ignorados em sua versão final homologada em 2017.

A aprovação da BNCC será determinante na eventual falta de execução de projetos e ações de Educação Ambiental no ensino formal, pois ela não torna clara a necessidade do alinhamento das propostas curriculares locais (Estaduais, Municipais e Projetos Político-Pedagógicos das escolas) com essa temática. Como veremos no estudo de caso da Rede Municipal do município de São Paulo, a influência da aprovação da Base Nacional Comum Curricular pelo Conselho Nacional de Educação foi direta, e afetou significativamente a possibilidade de uma boa prática pedagógica em Educação Ambiental. 


\section{A Educação Ambiental no Currículo da Rede Municipal de São Paulo}

A Lei no 15.967 / 2013 implementa a Política Municipal de Educação Ambiental de São Paulo (PMEASP) e entende a Educação Ambiental como um processo contínuo e permanente de aprendizagem, participação e formação, individual e coletivamente, com métodos participativos e interdisciplinares de ação reflexiva e crítica. , construindo valores, conhecimentos, habilidades, atitudes e competências. Atribui ao município a responsabilidade pelo desenvolvimento interdisciplinar, contínuo e permanente da Educação Ambiental nas diferentes fases do ensino, previstas nos projetos políticopedagógicos (PPP) (SÃO PAULO, 2014).

Em 2017, mesmo com a homologação da BNCC ter ocorrido no dia 20/12/2017, a aprovação do novo Currículo Municipal de São Paulo (SP) se deu 5 dias antes, sob a influência da $3^{\text {a }}$ versão (ainda preliminar), em 15/12/2017, fazendo com que fosse o primeiro município do país a publicar um Currículo já alinhado com a Base Nacional Comum Curricular. Segundo dados da Prefeitura Municipal, o processo de elaboração reuniu cerca de 200 professores e especialistas de todas as áreas de conhecimento.

O currículo da cidade (SÃO PAULO, 2017) parte de uma concepção de aprendizagem baseada em direitos que visam garantir o acesso e a aquisição de conhecimento para todas as crianças e jovens para a construção de uma sociedade mais solidária e justa. Baseia-se, também, nos objetivos de aprendizagem desenvolvidos e retoma os princípios estabelecidos nos direitos de aprendizagem dos Ciclos Interdisciplinar e Autoral (SÃO PAULO, 2016a), nos documentos Elementos Conceituais e Metodológicos para Definição dos Direitos de Aprendizagem e Desenvolvimento do Ciclo de Alfabetização (BRASIL, 2012), e nas Diretrizes Curriculares Nacionais (BRASIL, 2013). Sugere formas de trabalho em sala de aula por meio de orientações didáticas e promove a formação continuada de educadores e outros profissionais da rede municipal. Seu objetivo é alinhar as diretrizes curriculares da cidade de São Paulo ao processo de construção da Base Nacional Comum Curricular (BNCC), e, também, desenvolver habilidades socioemocionais, que estão descritas em sua Matriz de Saberes, que incluem empatia e cooperação, abertura à diversidade, autoconhecimento e autocuidado (PEREIRA, 2019).

Um ponto positivo a ser apontado no Currículo da Cidade de São Paulo comparado com a BNCC é que ele "incorporou os dezessete Objetivos de Desenvolvimento Sustentável (ODS), pactuados na Agenda 2030 pelos países membros das Nações Unidas, como temas inspiradores a serem desenvolvidos pelos diferentes componentes curriculares" (SÃO PAULO, 2017, s.p.), algo que em nenhuma parte da BNCC é citado. A Agenda é "um plano de ação que envolve todos para um caminho sustentável com medidas ousadas e transformadoras; e visa um plano de ação que envolve pessoas, o planeta, prosperidade, paz e parceria" (UNESCO, 2017, s.p.).

Teoricamente, o currículo de São Paulo prevê que as escolas poderão abordar, de maneira mais enfática, a questão ambiental. A Base Curricular de 
São Paulo foi dividida em nove arquivos diferentes, com nomes que remetem diretamente as disciplinas na escola ou que é facilmente identificada a área de atuação. Cada um desses documentos varia de 100 a 184 páginas (SÃO PAULO, 2017). São, de fato, documentos com uma grande quantidade de informações, abordando competências, eixos estruturantes, objetos de aprendizagem, entre outros diversos pontos.

Porém quando se trata de Educação Ambiental, apenas um dos arquivos tem uma referência ao tema, sendo este o relacionado à Matemática. A Educação Ambiental é citada dentro dos Eixos Articuladores como Conexões Extra Matemática, com o objeto de conhecimento sendo "Matemática e Educação Ambiental: vida na água", relacionando-o com os Objetivos do Desenvolvimento Sustentável, principalmente com esses temas: "combate às alterações climáticas" e a "vida debaixo d'água" (SÃO PAULO, 2017).

Segundo Dall'Onder (2018, p. 195), a Educação Ambiental, na escola,

garantida pelas diversas legislações educacionais, quando comprometida com a abordagem crítica, pode viabilizar alternativas para a sustentabilidade, desenvolvendo nos alunos a participação e a corresponsabilização pela transformação social, conservação do ambiente e manutenção da biodiversidade.

Baeder et al. (2000) defendem que a escola deve ser um espaço democrático e aberto para que os atores que nela atuam possam desenvolver ações por meio do diálogo que permitam aos ambientalistas atuar dentro e fora da sala de aula. Com a criação de uma cultura de participação para todos, consolidar-se-ão melhorias nas condições efetivas de enquadramento dessa ação (FREIRE, 2000; LUIZ, 2010).

Segundo Gohn (2006), em uma escola pública é necessário harmonizar a cultura do cotidiano e a aprendizagem vivenciada por meio das interações com a cultura adquirida, e isso se faz por meio do conhecimento, do conteúdo e da capacidade de pensamento, uma vez que o processo de aprendizagem na instituição não se dá apenas no seu espaço físico.

Dentre diversos espaços que garantam a formação de cidadãos, as escolas devem ser responsáveis por valorizar uma gestão democrática que assegure a participação de toda comunidade escolar na construção do Projeto Político-Pedagógico (PPP), no Grêmio Estudantil, na Associação de Pais e Mestres e nos Conselhos Formais de Escola (BRASIL, 1996).

A avaliação das lideranças democráticas deve ser da responsabilidade das escolas, para que a comunidade escolar seja envolvida no desenvolvimento do Projeto Político-Pedagógico (PPP), nos conselhos de escola, na associação de pais e professores, na associação de alunos, entre outros locais onde a educação dos cidadãos de Garantia (BRASIL, 1996). 
Por PPP entende-se a própria organização do trabalho educativo da escola. Este projeto vai além do simples agrupamento de planos e atividades de estudos, pois deve ser construído e vivenciado em todos os momentos e por todos os envolvidos no processo educativo da escola. Seu objetivo principal é dar um direcionamento, uma ação intencional, e por isso é considerado um "projeto político" por estar intimamente relacionado às obrigações sociais e políticas, aos interesses reais e coletivos da comunidade na qual a escola está inserida. E, por fim, é "pedagógico" por estar envolvido em um processo permanente de reflexão e discussão sobre os problemas escolares (VEIGA, 2002).

As escolas da cidade de São Paulo, obrigadas que são de elaborarem seus PPP, precisam contar com o trabalho cooperativo professores, diretores, coordenadores educacionais e diretores assistentes para sua adequada preparação e implementação coletiva (PEREIRA, 2019). Em sua elaboração e implantação, portanto, são os PPP que de fato concretizam o ensino da forma como ele se dará, sendo o espaço possível onde lacunas e ausências existentes nas Diretrizes superiores podem ser supridas. Eis aqui a oportunidade de inserir, como se deve e como prevê a lei, a Educação Ambiental de modo transversal e interdisciplinar.

Por se constituir em um roteiro de atividades de uma determinada disciplina durante o período do curso, seja semestral ou anual, Libâneo et al. (2009) defendem que um plano de ensino precisar estar voltado para as especificidades de cada grupo de alunos, e deve conter, além dos objetivos gerais e específicos, dos conteúdos, e dos procedimentos (as estratégias metodológicas, as técnicas), os recursos didáticos e processos de avaliação, além de poder ser para melhor se ajustar ao processo ensino e aprendizagem, ao longo de sua execução (SPUDEIT, 2014). Mais do que um mero documento técnico e cumpridor de uma burocracia, os planos devem ter seus objetivos realizados por meio de ações intencionais que indiquem soluções para as necessidades da escola (VEIGA, 2002; SÃO PAULO, 2016b).

Por fim, vale ressaltar que, na prática, a Educação Ambiental está ainda pouco presente no atual currículo do município de São Paulo. Para contemplála, a comunidade escolar deverá inserir debates e práticas interdisciplinares com uma concepção de Educação Ambiental vinculada ao Projeto PolíticoPedagógico. Desse modo, ficará registrada e estabelecida sua execução, dando grande possibilidade de se abranger um maior número de docentes e discentes.

Nesse sentido, a escola deverá buscar reflexões entre a teoria e a sua prática, debatendo qual concepção de meio ambiente e de Educação Ambiental almeja atingir. Este pode ser um caminho para se buscar a tão sonhada transformação da sociedade em relação ao meio ambiente. 


\section{Considerações finais}

Medidas ambientais são recomendadas para melhorar o meio ambiente e a qualidade de vida das comunidades. Recolher o lixo nas praças, plantar e monitorar o crescimento das novas árvores, catalogar árvores antigas, e criar cartazes de conscientização nas escolas são atitudes possíveis de ativistas ambientais, pessoas cuja prática da observação ambiental Ihes permitem percebem que algo está errado e, por isso, agem para melhorar a vida de todos (BAEDER et al., 2000). Ser ativista ambiental vai além de olhar para a natureza: significa planejar ações que procurem envolver as pessoas no debate e agir onde você estiver. Embora não sejamos os únicos responsáveis por transformar valores e atitudes, é possível fazer algo para construir uma sociedade sustentável (FREIRE, 1996, GADOTTI, 2009).

Para compreender o que é o meio ambiente, Reigota (2005) recomenda que nas atividades da área de Educação Ambiental deve-se ter o entendimento das Representações Sociais (RS). Por Representação Social entende-se um conjunto de princípios segundo os quais as pessoas interagem e compartilham em grupos sociais. São elas que proporcionam a percepção do conceito de ambiente, classificando-o em três tipos: o naturalista, em que o ambiente é caracterizado apenas por seus aspectos naturais, é a natureza intacta; o antropocêntrico, em que o meio ambiente se caracteriza como fonte de recursos naturais; e a globalização, onde o meio ambiente é formado pela natureza e pela sociedade.

Segundo estudos envolvendo professores de escola pública do ensino fundamental que vêm sendo realizados na área das Representações Sociais e reflexões sobre a preocupação com a preservação e a conservação ambiental, a Educação Ambiental pode ser um objeto transformador na qualidade de vida dos envolvidos, caso seja desenvolvida como prática interdisciplinar cotidiana na escola, pois ela é uma ferramenta facilitadora no processo dialógico entre os professores e alunos (COELHO MONTEIRO; MONTEIRO, 2017).

Pedrini, Costa e Ghilardi (2010) realizaram uma análise dos desenhos sobre o que é meio ambiente em um grupo de crianças e, observaram que elas - representam pela presença ou ausência de macrocompartimentos socioambientais (natural, artificial e abstrato), divididos em macroelementos (atmosfera, terrestre, aquático, fauna, flora, urbano) compostos por símbolos (casa, nuvens, lago, homem, bicicleta etc.) que revelavam como eles percebiam seu meio e suas inter-relações de dependência (PEDRINI; DEPAULA, 2008).

Buscar a criticidade da própria ação e a conexão ou afetividade com o local pode reinserir o humano como parte integrante do seu ambiente (FREIRE, 1996; TUAN, 2012). Esse é um viés que se compromete com a formação de sujeitos ambientalmente responsáveis, no qual a educação é "balizada nas decisões sociais e reorientadora dos estilos de vida coletivos e individuais [...], delineiam-se novas racionalidades, constituindo os laços identitários de uma cultura política ambiental' (CARVALHO, 2004, p. 16).

Revbea, São Paulo, V. 16, № 6: 321-347, 2021. 
Considerado que, segundo Freire (1998) nenhuma educação é neutra, e que que ela sendo crítica, ou seja, relacionada com uma posição política que compreende as relações sociais historicamente estabelecidas pelos sujeitos na sociedade, e contribui para um movimento de transformação desta sociedade para mais justa e igualitária (FREIRE, 1996), a Educação Ambiental deve caminhar no sentido de que os sujeitos do processo educativo se envolvam na busca de solução ou melhoria para os problemas e conflitos, formando uma cidadania ambiental por meio de processos de ensino-aprendizagem que preconizem a construção significativa de conhecimentos. (CARVALHO, 2004).

Para Guerra e Silva (2012, p. 200), a cidadania relaciona-se com a cultura de um povo que apresenta aspectos materiais e imateriais, "tais como vestuário, alimentos, crenças, maneiras de pensar, de morar, de se locomover, a linguagem, as religiões, instituições de todos os tipos, maneiras de sentir, tradições e costumes".

A transversalidade e a interdisciplinaridade claramente preconizadas nos Parâmetros Curriculares Nacionais (BRASIL, 1997) são características fundamentais quando os assuntos são desafios sistêmicos e complexos. Apesar disso, Biólogos e Geógrafos continuam sendo a linha de frente das inciativas em Educação Ambiental, tanto na esfera privada, quanto na pública. Uma vez que os desafios socioambientais possuem em sua base os valores, atitudes e comportamentos humanos, parece razoável que áreas como as Ciências Sociais, a Psicologia, o Direito, a Sociologia, entre outras, sejam parte integrante desse processo de transformação. Infelizmente, ainda estamos distantes da realidade de uma atuação mais profunda e complementar.

Precisamos, enquanto educadores, pensar em um novo "tripé da sustentabilidade" focado na participação, na co-criação e na coresponsabilização, componentes que podem influenciar positivamente mudanças metodológicas e estruturais sobre como pensamos, criamos e avaliamos os diferentes processos em Educação Ambiental (GRANDISOLI, 2018; GRANDISOLI et al., 2020).

Além disso, é preciso, mais do que nunca, marcar presença no debate sobre as políticas públicas educacionais, de modo a não permitir retrocessos no campo ambiental, e fortalecer, cada vez mais, a Educação Ambiental nos espaços formais e não formais.

Novos horizontes no terreno educacional estão sendo implementados, revestidos de sentidos e significados que são interpretados de inúmeras formas pelos atores deste processo. Por um lado, temos os decisores das políticas públicas em educação que, baseados mais em "crenças do que em ideias" decidem "soluções disponíveis ou que previamente se pretende implementar" (BARROSO, 2009, p.991). De outro lado, temos os atores em suas diversas funções da área educacionais, dentre eles os educadores ambientais, que interpretam e tentam realizar as orientações e dinâmicas, exigidas, nos espaços educacionais. 
No Brasil, especificamente no que se refere à educação pública, os atores que participam na área educacional demonstram algum conhecimento destas orientações. Entretanto, não existe unicidade, nem nos discursos locais e, nem nos discursos nacionais. Sem a presença de afinidades nos discursos das políticas públicas de educação, que mudam constantemente por meio do entendimento das políticas partidárias sobre o tema, revela-se a liquidez do projeto de Nação.

A busca de consensos e diálogos deve ser algo permanente em nosso século. Sabe-se que a lógica neoliberal está presente na área educacional, entretanto, acreditamos que se houver a apropriação de conhecimentos pertinentes sobre o papel e a função de seus atores, as dinâmicas terão ritmo e equilíbrio e, consequentemente um melhor aproveitamento dos espaços escolares.

Portanto, as conotações e diferenças semânticas que residem nos conceitos de 'servidores públicos' e 'agentes públicos' deveriam ser papéis e funções apreciadas por estudos. As interpretações destes conceitos, difundidas, sobrepujariam as práticas de ação por meio das dinâmicas e espaços do meio educacional, incluindo aqui a Educação Ambiental nas escolas.

Entendemos que, os atores/sujeitos da educação possuem histórias de vida e identidades profissionais que, por vezes os fazem, não como protagonistas, mas como atores vis dos processos em que se encontram no atual cenário educacional. Carregam em si, responsabilidades e sobrecargas de trabalho que os impedem de refletir sobre suas profissões e atuações pedagógicas, bem como na apreensão das políticas públicas de educação e dos processos de gestão educacional. E no caso dos que trabalham com Educação Ambiental, ainda se soma a difícil tarefa de rediscutir os paradigmas e projetar um novo futuro para os alunos e a sociedade.

Contata-se, assim a hercúlea tarefa dos educadores oriundos, especificamente, da escola pública, circunstanciados pelo: número excessivo de alunos por sala de aula; burocracias administrativas; desvalorização salarial que, por vezes, os levam a trabalhar em três períodos escolares; e, a falta de reconhecimento social; a falta de tempo e espaço adequados para seus estudos, formação pedagógica e preparação de aulas. Portanto, refletir sobre as novas dinâmicas que estão sendo assimiladas em sua atividade laboral é um desafio muitas vezes inimaginável. E pior, com a chegada de novas diretrizes educacionais via Base Nacional Comum Curricular, recebem mais teorias e estratégias "inovadoras" com as quais precisam lidar, sem estarem devidamente preparados para isso.

Circunscritos neste cenário de muitas vozes como a instalação de Babel, de Cildo Meireles, ficam imobilizados e assistem 'passivamente' a internalização das novas prerrogativas educacionais - dinâmicas - que influenciarão direta e indiretamente suas práticas pedagógicas, tais como o Angelus Novus de Paul Klee em sua perplexidade ao ser lançado para um 
futuro do qual não foi inserido suas percepções e realidades escolares. São os limites e as fronteiras que nos aproximam e nos distanciam por não haver o diálogo que faz sentido e significado na aprendizagem da Educação Ambiental, pertinente à nossa continuidade no planeta.

\section{Referências}

ABREU, Y. V.; OLIVEIRA, M. A. G.; GUERRA, S. M. G. Energia Sociedade e Meio Ambiente. Málaga - Espanha: Eumed. Net, Universidad de Málaga, 2010. 175 p.

ABRIC, J. C. A abordagem estrutural das representações sociais. In: MOREIRA, A. S. P.; OLIVEIRA D. C. (Org.). Estudos interdisciplinares de representação social. Tradução de Pedro Humberto Faria Campos. 2. ed. Goiânia: AB, 2000. p. 307.

ANDRADE, M.C.P.; PICCININI, C. L. Educação Ambiental na Base Nacional Comum Curricular: retrocessos e contradições e o apagamento do debate socioambiental. Anais do IX EPEA - Encontro Pesquisa em Educação Ambiental. Juiz de Fora - MG, 2017.

BACICH, L.; MORAN, J. (Orgs.). Metodologias ativas para uma educação inovadora: uma abordagem teórico-prática. Porto Alegre: Penso, 2018. 238 p.

BAEDER A. M. et al. Jovens em ação! Ações para melhorar o ambiente e a qualidade de vida nas cidades. São Paulo: Companhia Melhoramentos, 2000.

BARBOSA, G.S. O Desafio do Desenvolvimento Sustentável. Revista Visões 4 edição. Rio de Janeiro, v. 1, n. 4, 2008.

BARBOSA, L.C. Políticas Públicas de Educação Ambiental numa sociedade de risco: Tendências e desafios no Brasil. Brasília, 2008. 21p.

BARDON, J.; QUEIROLO, G.; SALDAÑA, P. Base Final: Entenda o que diz a versão definitiva da Base Curricular e o que falta para ela chegar às salas de aula de todo 0 país. 2017. Disponível em: $<$ http://arte.folha.uol.com.br/cotidiano/2017/12/21/base-final/> Acesso em: 20 mai. 2020.

BARROSO, J. A utilização do conhecimento em política: O caso da Gestão Escolar em Portugal. Campinas, 2009. Disponível em: $<$ http://www.scielo.br/pdf/es/v30n109/v30n109a04.pdf > Acesso em: $15 \mathrm{fev}$ 2018.

BARROSO, J. A Regulação das políticas Públicas de Educação: Espaços, Dinâmicas e Atores. Lisboa, 2006. 262p.

BARROSO, J. O Estado, a Educação e a Regulação das Políticas Públicas. Educ. Soc., Campinas, vol. 26, n. 92, p. 725-751, Especial - Out. 20058 BAUMAN, Z. Capitalismo Parasitário. Tradução de Eliana Aguiar. Rio de Janeiro: Zahar, 2010. 92p. 
BAUMAN, Z. Retrotopia. Tradução de Renato Aguiar. Rio de Janeiro: Zahar, 2017. 164p.

BERGER, P. I.; LUCKMANN, T. A construção social da realidade: tratado de sociologia do conhecimento. 33. ed. Tradução de Floriano de Souza Fernandes. Petrópolis: Vozes, 2011. 239p.

BERGER, P. L. Perspectivas Sociológicas: uma visão humanística. Tradução de Donaldson M. Garschagen. 31ª edição. Petrópolis: Vozes, 2011.

BRASIL. Ministério do Meio Ambiente. Agenda 21 Global, s.d. Disponível em $\leq$ https://antigo.mma.gov.br/responsabilidade-socioambiental/agenda-21/agenda21-global.html>, acesso em: 16 nov. 2021.

BRASIL, Ministério da Educação e do Desporto. Parâmetros Curriculares Nacionais: Terceiro e Quarto ciclos do ensino fundamental. Brasília: MEC, Secretaria de Educação Fundamental, 1997.

BRASIL, Ministério da Educação. A Base Nacional Comum Curricular Apresentação. Brasília: MEC. 2017. Disponível em: <http://basenacionalcomum.mec.gov.br/a-base >. Acesso em: 16 nov. 2021.

BRASIL, Ministério da Educação. Secretaria de Educação Básica. Elementos conceituais e metodológicos para definição dos direitos de aprendizagem e desenvolvimento do ciclo de alfabetização (1, $2^{\circ}$ e $3^{\circ}$ anos) do ensino fundamental - Brasília: MEC, 2012. 137p. Disponível em $<$ http://portal.mec.gov.br/index.php?option=com docman\&view=download\&alia $\mathrm{s}=12827$-texto-referencia-consulta-publica-2013-cne-

pdf\&category slug=marco-2013-pdf\&ltemid=30192 > . Acesso em 21 de maio de 2020.

BRASIL, Ministério da Educação. Secretaria de Educação Básica. Secretaria de Educação Continuada, Alfabetização, Diversidade e Inclusão. Conselho Nacional da Educação. Diretrizes Curriculares Nacionais Gerais da Educação Básica/ Ministério da Educação. Secretária de Educação Básica. Diretoria de Currículos e Educação Integral. - Brasília: MEC, SEB, DICEI, 2013. 542p.

BRASIL. Lei n. 9.795, de 27 de abril de 1999. Dispõe sobre a Educação Ambiental, institui a Política Nacional de Educação Ambiental e dá outras providências. Diário Oficial da República Federativa do Brasil, Brasília, 28/04/99.

BRASIL. Lei número 9.394 de 20 de Dezembro de 1996. Disponível em: $<$ portal.mec.gov.br/seesp/arquivos/pdf/lei9394 ldbn1.pdf>. Acesso em 22 nov. 2017.

BRASIL. Ministério da Educação. Base Nacional Comum Curricular. Brasília (DF). 2018. Disponível em: <http://basenacionalcomum.mec.gov.br/wpcontent/uploads/2018/12/BNCC 19dez2018 site.pdf>. Acesso em: 1 set. 2018.

BRASIL. Plano Nacional de Educação. Disponível em: <http://www.planalto.gov.br/CCIVIL 03/ Ato2011-2014/2014/Lei/L13005.htm>.

Acesso em: 26 fev 2018.

Revbea, São Paulo, V. 16, № 6: 321-347, 2021. 
CARVALHO, I. C. M. C. Educação Ambiental crítica: nomes e endereçamentos da educação. In: PHILIPPE, P. L. (coord.). Identidades da Educação Ambiental brasileira. Ministério do Meio Ambiente. Diretoria de Educação Ambiental; Brasília: Ministério do Meio Ambiente, p. 13-24, 2004.

COELHO MONTEIRO, I.F.; MONTEIRO, P.D.E.B.S.C.O. A Educação Ambiental e as representações sociais dos professores da rede pública no ensino fundamental. Revista Brasileira de Educação Ambiental, São Paulo, v. 12, n. 1, p. 165-176, 2017.

CZAPSKI, S. A Implantação da Educação Ambiental no Brasil. Brasília: Coordenação de Educação Ambiental, Ministério da Educação, 1998. 166p.

DALL'ONDER, A. Educação Ambiental e resíduos sólidos: um estudo nas escolas públicas municipais de São Paulo. 2018. Dissertação (Mestrado em Sustentabilidade) - Escola de Artes, Ciências e Humanidades, Universidade de São Paulo, São Paulo, 2018. Disponível em: $<$ http://www.teses.usp.br/teses/disponiveis/100/100136/tde-09042018-

095938/>. Acesso em: jun. 2018.

DOURADO, L. F. Políticas e Gestão da Educação Básica no Brasil: Limites e Perspectivas. Educ. Soc., Campinas, vol. 28, n. 100 - Especial, p. 921-946, out. 2007.

FREIRE, P. Pedagogia do oprimido: saberes necessários a práticas educativas. São Paulo: Paz e Terra, 1996.

FREIRE, P. Por uma pedagogia da pergunta. São Paulo: Paz e Terra, 1998.

GADOTTI, M. Educar para a sustentabilidade: uma contribuição à década da educação para o desenvolvimento sustentável. São Paulo: Instituto Paulo Freire, Série Unifreire; 2, 2009.

GOHN, M. G. Educação não formal, participação da sociedade civil e estruturas colegiadas nas escolas. Ensaio: Aval. Pol. Públ. Educ., v. 14, n. 51, p. 27-38, jan./mar. 2006. Disponível em: <http://escoladegestores.mec.gov.br/site/8biblioteca/pdf/30405.pdf>. Acesso em: 23 jan. 2018.

GRANDISOLI, E. Projeto Educação para a Sustentabilidade: transformando espaços e pessoas. Uma experiência de sete anos no ensino médio. Tese de doutorado. IEE-USP; orientador: Pedro Roberto Jacobi. - São Paulo, 2018.

GRANDISOLI, E. Aprendizagem por desafios: conectando pessoas e contextos. 2019. Disponível em <https://respostasparaoamanha.com.br/ noticias/categoria/4/tudo-sobre-o-premio/noticia/25/aprendizagem-por-desafiosconectando-pessoas-e-contextos/>. Acesso em 21 de abril de 2020.

GRANDISOLI, E.; SOUZA, D. T. P.; MONTEIRO, R. A. A.; JACOBI, P. R. Participação, cocriação e corresponsabilidade: um modelo de tripé para a educação para a sustentabilidade. In: GRANDISOLI, E.; SOUZA, D. T. P.; JACOBI, P. R.; MONTEIRO, R. A. A. (orgs.) Educar para a sustentabilidade: visões de presente e futuro. São Paulo: IEE-USP: Reconectta: Editora Na Raiz, 2020. 
GUERRA, L. D.; SILVA, J. B. Cultura e desenvolvimento: uma visão crítica dos termos do debate. In: BRASILEIRO, M. D. S.; MEDINA, J, C. C.; CORIOLANO, L. N. (orgs.). Turismo, cultura e desenvolvimento [online]. Campina Grande: EDUEPB, pp. 195-233, 2012.

GUIMARÃES, M. A Formação de Educadores Ambientais. Campinas: Papirus, 2004.

GURSKI, B. ROBERTO, G. TENDOLINI, P. Conferência de Estocolmo: Um marco na Questão Ambiental. Revista Unicuritiba, v. 11, n. 12, 2012.

HOY, W. K. Administração Educacional: teoria, pesquisa e prática. Tradução: Henrique de Oliveira Guerra. 9aㅡ ed. Porto Alegre: 2015. 519p.

JACOBI, P. R.; TOLEDO, R. F.; GRANDISOLI, E. Education, sustainability and social learning. Brazilian Journal of Science and Technolog, v.3, n.3, 2016.

JACOBI, P.R.; GUERRA, A.F.S.; SULAIMAN, S.N.; NEPOMUCENO, T. Mudanças Climáticas Globais: a resposta da educação. Revista Brasileira de Educação, v.16, n. 46, 2011.

KELLERT, S. R. Experiencing nature: affective, cognitive and evaluative development in children. In: KAHN, P. H.; KELLERT, S. R. Children and nature. Psychological, sociocultural, and evolutionary investigations. MIT, 2002.

KOPNINA, H. Education for the future? Critical evaluation of education for sustainable development goals. The Journal of Environmental Education, v.51, Issue 4, 2020.

LAYRARGUES, P. P. Muito além da natureza: Educação Ambiental e reprodução social. In: LOUREIRO, C. F. B.; LAYRARGUES, P. P.; CASTRO, R. C. de (orgs). Pensamento complexo, dialética e Educação Ambiental. São Paulo: Cortez, pp. 72-103, 2006.

LAYRARGUES, P. P.; LIMA, G. F. C. Mapeando as macrotendências políticopedagógicas da Educação Ambiental contemporânea no Brasil. Ambiente \& Sociedade, São Paulo, v. XVII, n. 1, pp. 23-40, 2014.

LEFF, H. Complexidade, interdisciplinaridade e saber ambiental. In: PHILIPPI Jr. A. et al. Interdisciplinaridade em Ciências Ambientais. São Paulo: Signus, p. 179, 2000.

LEMES, S.S. Indagações sobre as políticas educacionais e reflexões sobre demandas percebidas pelo estado brasileiro: tópicos para análise circunstanciada de seus instrumentos de ação. Revista lbero-Americana de Estudos em Educação, v. 11, n. esp. 3, p.1616-1625, 2016.

LIBÂNEO, J. C.; OLIVEIRA, J. F.; TOSCHI, M. S. Educação Escolar: políticas, estrutura e organização. 8. ed. São Paulo: Cortez, 544 p, 2009.

LOUREIRO, C. F. B. et al., Contribuições da teoria marxista para a Educação Ambiental crítica. Cadernos Cedes, Campinas, vol. 29, n. 77, p. 81-97, jan./abr. 2009. 
LUCAS, A. M. The role of Science Education in Education for the Environment. The Journal of Environmental Education, v.12, n.2, p.33-37, 1980.

MINTZBERG, H. Estrutura nas Escolas. In: HOY, W. K. Administração Educacional: teoria, pesquisa e prática. Tradução: Henrique de Oliveira Guerra. 9a ed. Porto Alegre: 2015. 519p.

MORAN, J. Metodologias ativas para uma aprendizagem mais profunda. In: BACICH, L.; MORAN, J. (Orgs.) Metodologias ativas para uma educação inovadora: uma abordagem teórico-prática. Porto Alegre: Penso, 2018.

MORAN, J. Mudando a educação com metodologias ativas. In: SOUZA, C. A.; MORALES, O. E. T. Convergências Midiáticas, Educação e Cidadania: aproximações jovens. Coleção Mídias Contemporâneas, v.II, PROEX/UEPG, 2015.

MORITZ, G. O.; MORITZ, M. O.; PEREIRA, M. F. Planejamento por Cenários Prospectivos: Referencial Metodológico Baseado em Casos para a Aplicação Prática nas Organizações. São Paulo, SP: Atlas, 2012. 111p.

MOSCOVICI, S. Representações sociais: investigações em psicologia social. Tradução de Pedrinho A. Guareschi. Petrópolis: Vozes, 2003. 404 p.

NOVICKI, V.; SOUZA, D.B. Políticas públicas de Educação Ambiental e a atuação dos conselhos de meio ambiente no Brasil: perspectivas e desafios. Ensaio: aval.pol.públ.Educ., v.18, n.69, Rio de Janeiro Oct./Dec. 2010.

OLIVEIRA, L, D. A Conferência do Rio de Janeiro - 1992 (Eco-92): reflexões sobre a geopolítica do desenvolvimento sustentável. Disponível em: $<$ http://www.anppas.org.br/encontro6/anais/ARQUIVOS/GT15-170-31-3120120626115525.pdf>. Acesso em: 25 ago. 2017.

OLIVEIRA, L. D. A Geopolítica do Desenvolvimento Sustentável na CNUMAD - 1992 (Eco-92): entre o Global e o Local, a Tensão e a Celebração. Revista de Geopolítica, Ponta Grossa, PR, v. 2, n. 1, p. 43 - 56, jan./jun. 2011b.

OLIVEIRA, L. D. A Geopolítica do Desenvolvimento Sustentável: um estudo sobre a Conferência do Rio de Janeiro (Rio-92), 2011. 283 p. Tese (Doutorado em Geografia). Instituto de Geociências, Universidade Estadual de Campinas (UNICAMP), Campinas, SP, 2011 a.

OLIVEIRA, L. D. Da Eco-92 à Rio + 20: uma breve avaliação de duas décadas. Boletim Campineiro de Geografia, v. 2, n. 3, 2012.

OLIVEIRA, L.; NEIMAN, Z. Educação Ambiental no Âmbito Escolar: Análise do Processo de Elaboração e Aprovação da Base Nacional Comum Curricular (BNCC). Revista Brasileira de Educação Ambiental, v.15, n.3, p.36-52, 2020.

OTERO, P. B. G.; NEIMAN, Z. Avanços e desafios da Educação Ambiental brasileira entre a Rio 92 e a Rio+20. Revista Brasileira de Educação Ambiental (online), v. 10, pp. 20-41, 2015.

PEDRINI, A. G; DE-PAULA, J. C. Educação Ambiental: críticas e propostas. In: PEDRINI, A. G. (Org.). Educação Ambiental: reflexões e práticas contemporâneas. 6. ed. Petrópolis: Vozes, p. 90-146, 2008.

revista brasileira educação ambiental 
PEDRINI, A.; COSTA, E.; GHILARDI, N. Percepção ambiental de crianças e pré-adolescentes em vulnerabilidade social para projetos de educação. Ciência \& Educação, v. 16, n. 1, p. 163-179, 2010.

PEREIRA, M.C.S. Educação Ambiental na perspectiva da intervenção social: abordagem interdisciplinar a partir do Projeto Ocupe a Praça (São Paulo-SP). Dissertação de Mestrado, Programa de Pós-Graduação em Análise Ambiental Integrada, Unifesp, Diadema, 2019. Disponível em $<$ https://repositorio.unifesp.br/handle/11600/56228>. Acesso em 17 out. 2021.

PHILLIPI JÚNIOR, A. et al. Interdisciplinaridade em ciências ambientais. São Paulo: Signus, 318 p. [Série textos básicos para a formação ambiental, 5], 2000.

RAMOS, E.C. Educação Ambiental: Evolução Histórica, Implicações Teóricas e Sociais. Uma Avaliação Crítica. 1996. 147 f. Dissertação de Mestrado em Educação na área de Concentração de Educação e Trabalho. Programa de Pós Graduação em Educação, Universidade Federal do Paraná, PR, 1996.

SÃO PAULO (Estado). Secretaria do Meio Ambiente. Diretrizes pedagógicas e programa municipal de Educação Ambiental. Texto Aline Danielle Paes Julião; Juliana Ferreira de Castro. São Paulo: SMA, 2014. Disponível em: $<$ http://arquivos.ambiente.sp.gov.br/cea/2014/11/diretizes-pedagogicas.pdf>.

Acesso em: 23 jun. 2018.

SÃO PAULO (Município). Currículo da Cidade. 2017. Disponível em: $<$ http://portal.sme.prefeitura.sp.gov.br/Portals/1/Files/47274.pdf>. Acesso em: 3 set. 2018.

SÃO PAULO (Município). Secretaria Municipal de Educação. Direitos de Aprendizagem dos Ciclos Interdisciplinar e Autoral. Coleção Componentes Curriculares em Diálogos Interdisciplinares a Caminho da Autoria. 72 p. 2016a. Disponível em: <http://portal.sme.prefeitura.sp.gov.br/Colecao-ComponentesCurriculares>. Acesso em: 3 set. 2018.

SÃO PAULO (Município). Secretaria Municipal de Educação. Projeto Político Pedagógico. São Paulo: Município de São Paulo, 2016b. Disponível em: $<$ http://portal.sme.prefeitura.sp.gov.br/Main/Noticia/Visualizar/PortalSMESP/ProjetoPolitico-Pedagogico>. Acesso em: 31 jan. 2016.

SAUVÉ, L. Educação Ambiental: possibilidades e limitações. Educação e Pesquisa, São Paulo, v. 31, n. 2, pp. 317-322, maio/ago. 2005b.

SAUVÉ, L. Uma cartografia das correntes em Educação Ambiental. In: SATO, M.; SAUVÉ, L. M.; CARVALHO, I. C. M. (Orgs.). Educação Ambiental: pesquisas e desafios. Porto Alegre: Artmed, 2005a.

SILVA THIESEN, J. A interdisciplinaridade como um movimento articulador no processo ensino-aprendizagem. Revista Brasileira de Educação, v. 13, n. 39, 2008. 
SILVA, A. F.; LEMES, S. S. Uma discussão com vistas ao desenvolvimento de um sistema online de avaliação do desempenho escolar: um estudo experimental sobre avaliação de desempenho escolar em rede. RPGE-Revista online de Política e Gestão Educacional, v.20, n.2, p. 271-281, 2016

SILVA, F.B.; CECCON, S.; GUNTZEL-RISSATO, C.; SILVEIRA, T.R.; TEDESCO, C.D.; GRANDO, J.V. Educação Ambiental: Interação no Campus Universitário através de Trilha Ecológica. Revista Eletrônica do Mestrado em Educação Ambiental, v. 17, 2006.

SILVA, M. P. Educação Ambiental para as séries iniciais. 2011. Trabalho de Conclusão de Curso. Universidade de Brasília, Brasília - DF, 2011.

SORRENTINO, M.; TRAJBER, R.; MENDONÇA, P.; JUNIOR, L. A. F. Educação Ambiental como política pública. Educação e Pesquisa, São Paulo, v. 31, n. 2, p. 285-299, 2005.

SPUDEIT, D. Elaboração do plano de ensino e do plano de aula, Universidade Federal do Estado do Rio de Janeiro - Unirio - Centro de Ciências Humanas E Sociais - CCH. Rio de Janeiro, fev. 2014.

TÁVORA, F.L. A Herança da Rio + 20. Senado Federal. Brasília. 2012. Disponível em: <https://www12.senado.leg.br/publicacoes/estudos.../tipos.../aheranca-da-rio-20>. Acesso em: 15 fev. 2018.

TUAN, Yi-Fu. Topofilia: um estudo da percepção, atitudes e valores do meio ambiente. Trad. de Lívia de Oliveira. Londrina: EdUEL, 2012.

UNESCO. Educação 2030: Declaração de Incheon e Marco de Ação para a implementação do Objetivo de Desenvolvimento Sustentável. 2017. Disponível em: $\quad<$ http://unesdoc.unesco.org/images/0024/002456/245656POR.pdf>. Acesso em: 19 jun. 2017.

UNESCO. Educação para os objetivos de desenvolvimento sustentável: objetivos de aprendizagem. Brasília: Unesco, 2017. Disponível em: $<$ http://unesdoc.unesco.org/images/0025/002521/252197por.pdf> Acesso em jun. 2018.

VEIGA, I. P. A. Projeto político-pedagógico da escola: uma construção possível. 14. ed. São Paulo: Papirus, 2002. 